\title{
A CNBB como promotora de notícia e fonte de informação da Igreja Católica no jornalismo: notas como ritual estratégico e meios alternativos de agendamento
}

\author{
Me. Eliane Muniz Lacerda* \\ Dr. Robson Dias** \\ Dr. Victor Márcio Laus Reis Gomes***
}

\section{Resumo}

Este artigo investiga notas e material de meios alternativos de agendamento midiático (1968-1977), feitos pela Conferência Nacional dos Bispos do Brasil (CNBB) e por bispos e instituições ligadas a ela, durante o período da ditadura militar, por meio de análise de conteúdo. A análise leva em conta, tematicamente, cinco casos de religiosos acusados pelo Estado de praticar atividades subversivas, publicados em Folha de S. Paulo, Jornal do Brasil, O Estado de S. Paulo e O Globo. O objetivo é resgatar a CNBB como ator no processo de produção da notícia (MOLOTCH e LESTER, 1999), além das ações tomadas como news promoters (assessores, organizações) ao se relacionar com os news assemblers (repórteres, editores e redatores), negociando sentidos a serem ofertados no noticiário aos news consumers (público leitor). Muito mais que fonte de notícias no espaço público e no espaço midiático, a CNBB participou ativamente em prol da cidadania, na luta pelos direitos humanos.

Palavras-chave: CNBB. Agendamento. Jornalismo. News Promoters. Rituais Estratégicos.

* Jornalista, mestre em Comunicação. Professora e pesquisadora do curso de Comunicação Social da Universidade Católica de Brasília (UCB). Vice-líder do Grupo de Estudos Prêmios, Indicadores e Estratégias em Comunicação (DGP/CNPq). eliane.muniz@gmail.com

** Jornalista, mestre e doutor em Comunicação. Pesquisador no Programa de Pós-Graduação em Comunicação, linha Processos Comunicacionais nas Organizações (PPGCOM/UCB). robson.dias@ucb.br

*** Publicitário, mestre em Administração e doutor em Comunicação. Pesquisador no Programa de Pós-Graduação em Comunicação, linha Processos Comunicacionais nas Organizações (PPGCOM/UCB). victorgomes.ucb@gmail.com 


\title{
CNBB as news promoter and source of information of the catholic church in the media space: notes as a strategic ritual and alternative Agenda Setting
}

\begin{abstract}
This article applies content analysis to investigate public notes and alternative means of media scheduling of the Conference of Bishops of Brazil (CNBB), and by bishops and institutions with bonds to this organization, during the military dictatorship in Brazil, with particular focus on the period 1968-1977. The analysis thematically revises five cases of religious figures accused by the state of practicing subversive activities, published in Folha de S. Paulo, Jornal do Brasil, O Estado de S. Paulo, and O Globo. The goal is to demonstrate how the $\mathrm{CNBB}$ has been a central actor in the news production process (MOLOTCH and LESTER, 1999), regarding news promotion (advisors, organizations), in relation to news assemblers (reporters, editors, redactions), and in negotiating what is offered to the news consumers (readership). Far beyond being just a source in the public and media space, the CNBB engaged actively in favor of citizenship and in the struggle for human rights.
\end{abstract}

Key-words: CNBB. Agenda Setting. Journalism. News Promoters. Strategic Rituals.

\section{Lugar de fala}

Este artigo contém levantamento da parte histórica da pesquisa de mestrado de Lacerda (2007), concentrada e alinhada à ideia de Jornalismo e Sociedade, no PPGFAC/UnB, que analisa a cobertura da imprensa durante a ditadura militar no Brasil, com base em cinco casos de religiosos acusados pelo regime militar de praticar atividades subversivas (1968-1977), a partir da análise de publicações do período, nos veículos: Folha de S. Paulo, Jornal do Brasil, O Estado de S. Paulo e O Globo (53 itens), pela perspectiva da Teoria da Notícia, da abordagem da Hipótese de Agenda-setting e do enquadramento de notícias. Os quatro jornais foram escolhidos por serem de circulação nacional, terem sobrevivido ao regime militar e por apresentarem presença mais constante que os demais veículos no arquivo jornalístico ${ }^{1}$ da Conferência Nacional dos Bispos do Brasil (CNBB).

Soares (1988, p. 270) afirma que, entre 1968 e 1978, 122 religiosos e 273 leigos foram presos e nove padres expulsos do Brasil. No arquivo jornalístico da CNBB, foi possível encontrar o registro de 18 casos de religiosos, que sofreram algum tipo de perseguição política durante a dita-

\footnotetext{
A proposta deste estudo iniciou com a descoberta do arquivo jornalístico da CNBB, com centenas de matérias sobre a atuação da Igreja Católica na ditadura militar. O arquivo é parte do Centro de Documentação e Informação da CNBB e está localizado na sede da instituição, em Brasília.
} 
dura no país. Destes, para esta pesquisa, foram selecionados cinco, sendo aqueles que tiveram maior e constante repercussão nos jornais já mencionados. Foram escolhidos os seguintes acontecimentos como objeto de estudo: 1) prisão por envolvimento com operários de Belo Horizonte-MG, em 1968, dos padres franceses Michel Le-Vem, Xavier Berthon, Hervé, Crouguennac e do seminarista José Geraldo da Cruz, todos da Congregação dos Agostinianos da Assunção; 2) prisão e tortura de religiosos dominicanos, em 1969, acusados de ligação com a União Nacional dos Estudantes e com o ex-deputado Carlos Marighella; 3) expulsão do padre francês François Jentel, em 1975, que atuava junto ao bispo de São Félix do Araguaia, dom Pedro Casaldáliga, na luta pela terra; 4) ameaças de expulsão do país de dom Pedro Casaldáliga, a partir de maio de 1977; 5) ameaças de expulsão do país do padre Romain Zufferri, em julho de 1977, por trabalhar com a Ação Católica Operária na arquidiocese de Olinda e Recife-PE.

O intuito deste artigo é, de modo descritivo, trazer à tona a atuação institucional e histórica da CNBB (nas décadas de 1960 e 1970) em relação ao jornalismo: uma entre outras tantas ações perenes em se pautar o noticiário no Brasil. Para tanto, resgatamos essa discussão para circulação e registro em bases indexadas, a partir da plataforma da Estudos de Religião. Uma contribuição ancorada em estudo empírico, análise documental, análise de conteúdo, enquadramento de agenda e de noticiário, na perspectiva da Teoria da Notícia (HALL, 1999; HACKETT, 1999; MCCOMBS, 2000; MOLOTCH, LESTER, 1999; TUCHMAN, 1999; MOTTA, 2004), na tradição dos estudos em Jornalismo e de Comunicação do Brasil e de Portugal.

\section{$\mathrm{O}$ agendamento da imprensa pela CNBB}

O posicionamento da igreja na imprensa, ante os acontecimentos com os religiosos acusados de praticar atividades subversivas, não foi unicamente uma questão de querer (ou não) emitir sua opinião. Esse problema praticamente obrigou a CNBB a assumir uma postura perante a sociedade. Apesar de ter apoiado o golpe de 1964, a instituição religiosa não consentiu com a forma repressiva dos militares, sobretudo quando a perseguição política atingiu religiosos, considerados comunistas pela ditadura militar. Logo, a igreja se viu na berlinda: de um lado, havia religiosos e leigos ameaçados, presos, torturados, expulsos e assassinados 1); de outro, o regime a acusava de não ter controle sobre sua base e, na qual, dizia haver comunistas infiltrados 2). Esses acontecimentos foram bastante significativos tanto para a imprensa como para a sociedade, uma vez que ocorreram em um país de maioria católica e 
também por ter sido a igreja, que outrora apoiara o golpe na luta contra o comunismo no Brasil, acusada de subversão.

Desde a perseguição a religiosos, a Igreja Católica adotou então uma postura mais ativa. Passou não só a se autodefender, mas também assumiu uma causa mais ampla: a defesa dos direitos humanos, violados pelo regime militar. Essa postura foi importante para a história do Brasil, pois, naquele momento, a igreja era uma das poucas instituições capazes de enfrentar as ações repressivas da ditadura. Nas notícias analisadas e em grande parte da literatura que embasou esta pesquisa foi possível perceber que bispos como dom Helder Câmara 1), dom Paulo Arns 2), dom Ivo Lorscheiter 3) e dom Aloísio Lorscheider 4) não silenciaram diante das ameaças da ditadura. "A CNBB tornou-se a voz nacional da Igreja brasileira, divulgando declarações críticas contra as violações dos direitos humanos e a injustiça social econômica. Dom Aloísio e dom Ivo eram os líderes mais importantes" (SERBIN, 2001, p. 321).

A CNBB conquistou, dessa forma, espaço na imprensa para denunciar e criticar, assumindo o papel de promotora de notícias, na disputa pela visibilidade no espaço público de mediação jornalística.

Segundo Molotch e Lester (1999, p. 38), os promotores da notícia são aqueles que "identificam [...] uma ocorrência como especial, com base em algo, por alguma razão, para os outros”. Geralmente, eles não trabalham em proveito próprio, mas em torno de assuntos de interesse público. Os promotores usam, muitas vezes, estratégias para agendar a mídia, como entrevistas coletivas, divulgação de press releases e de notas, procuram manter bom relacionamento com a imprensa, promovem prêmios de incentivo aos jornalistas. Outros agentes, como as ONGs e os movimentos sociais, precisam de estratégias mais chamativas para ocupar as páginas dos jornais. Exemplos recentes são os relacionados ao Greenpeace e ao Movimento dos Sem Terra, que adotam iniciativas impactantes para chamar a atenção da imprensa e, por conseguinte, da opinião pública.

Eventualmente, o trabalho de produção dos jornalistas coincide com o trabalho dos promotores de notícia. Conforme Hall (1999, p. 228), “os media não criam autonomamente as notícias [...] estão dependentes de assuntos noticiosos específicos fornecidos por fontes institucionais regulares e credíveis". Como afirmam Molotch e Lester (1999, p. 41), “existem paralelos entre as necessidades de acontecimentos dos news assemblers e os promotores". Essas necessidades, entretanto, podem surgir por diferentes razões e não significam que os jornalistas e os promotores "estejam conscientes das implicações do trabalho uns dos outros" (IDEM), mas "de qualquer modo, conseguem pro- 
duzir um produto que favorece as necessidades de acontecimentos de certos grupos sociais e desfavorece as de outros" (IDEM).

Isto foi exatamente o que ocorreu nos casos dos religiosos, acontecimentos que tiveram seus valores-notícia e, por conseguinte, mais facilidade de serem escolhidos pelos jornalistas para se tornarem notícias. Ao mesmo tempo, foram acontecimentos que atingiram diretamente a Igreja Católica, que sentiu a necessidade de posicionar-se em defesa da causa.

Como promotora de notícias, a instituição usou algumas estratégias simples para agendar a mídia, como entrevistas coletivas e individuais, porém o meio mais comum usado pela CNBB foi a publicação de notas. Dessa forma, a instituição religiosa garantia a não distorção dos seus pronunciamentos e evitava maiores conflitos com o Estado.

\section{Entrevistas coletivas e individuais}

As entrevistas eram mecanismos de intervenção da CNBB no espaço público e no espaço midiático, tentando atingir a pauta jornalística, o noticiário e, por conseguinte, a opinião pública. O corpus deste estudo leva em conta entrevistas coletivas e as declarações individuais à imprensa presentes em jornais analisados, no período de 1968 a 1977. Das 53 matérias, 38 fazem referência a algum tipo de entrevista coletiva ou individual. Metodologicamente, é difícil, entretanto, distingui-las, dado que as declarações prestadas pelos bispos não são apresentadas no formato entrevista (pergunta e resposta), nem é explicitado se o contato foi exclusivo ou coletivo. As entrevistas foram transformadas em notícias, na quais constam as falas das fontes de informação. O fato é que $71,6 \%$ das matérias mostram que a Igreja esteve bastante acessível para dar informações. Em apenas um dos casos, houve resistência da CNBB em se pronunciar a respeito: o dos religiosos dominicanos. A justificativa, segundo dom Aloísio Lorscheider, ${ }^{2}$ é que os acontecimentos surpreenderam a presidência da CNBB que tinha acabado de retornar do Vaticano. Conforme dom Lorscheider, tanto o presidente dom Agnelo Rossi, como ele próprio, então secretário geral, não tinham informações suficientes para se pronunciar sobre o assunto. Outro caso no qual a instituição não aparece em entrevistas é o do padre Jentel. O motivo foi a censura ao assunto, como mostram os bilhetinhos: ${ }^{3}$

2 Informação obtida em entrevista realizada, em 2006, como parte integrante do processo de apuração de Lacerda (2007).

Ordens emitidas pelos governos militares às empresas de comunicação. 
De ordem superior reitero determinação manter proibição total a noticiário, comentário, transcrição e outras matérias, através dos meios de comunicação social, escrito, falado e televisado, sobre padre Jentel ou assunto a ele vinculado direta ou indiretamente. 13/02/74 (MARCONI, 1980, p. 275).

O autor completa:

De ordem superior reitero determinação sentido manter proibição a divulgação, através dos meios de comunicação social, comentários, referências, transcrição, entrevistas e outras matérias, qualquer procedência, relativa ao padre François Jentel. 23/05/75 (MARCONI, 1980, p. 281).

Somente em dois casos foi possível identificar claramente a técnica jornalística de captação das informações: a entrevista coletiva. O primeiro caso, em 1968, quando o arcebispo de Belo Horizonte, dom João Rezende Costa, após uma reunião com os padres da arquidiocese, resolveu falar publicamente à imprensa sobre a prisão dos religiosos assuncionistas.

Reafirmando sua confiança aos padres detidos, o arcebispo de Belo Horizonte, d. João Rezende Costa, e o Conselho Presbiteral da Arquidiocese, em entrevista à imprensa, consideraram insuficientes as provas apresentadas pelo Exército e concluíram que os padres 'foram detidos por causa dos pobres' (O ESTADO DE S. PAULO, 7/11/68).

O outro caso se relaciona ao dos dominicanos. Quase um mês depois da prisão desses religiosos, o presidente da CNBB, dom Agnelo Rossi, convocou a imprensa para a divulgação de um disco, mas, obviamente, a expectativa dos jornalistas voltou-se para a prisão dos religiosos. Um único trecho da matéria fez referência ao disco:

O cardeal havia convocado a imprensa para solicitar a divulgação de uma notícia sobre um disco, 'Poemas para rezar', que será vendido em benefício do Congresso Eucarístico Nacional a ser realizado em Brasília (O ESTADO DE S. PAULO, 6/12/69).

O restante do conteúdo abordou a fala de dom Rossi sobre a prisão dos padres. De todas as entrevistas observadas, esta parece a única entrevista coletiva para a qual a imprensa foi convocada formalmente e, durante a qual, o bispo apresentou um discurso já pronto sobre os dominicanos, ape- 
sar de a pauta ser o lançamento do disco. A respeito deste caso, na grande maioria das vezes, a CNBB manifestou-se por meio de notas e atendeu à imprensa ocasionalmente, por exemplo, no aeroporto ou após reunião com alguma autoridade. Pelo que se observou por meio da leitura das matérias referentes aos casos, esta entrevista era aguardada pelos profissionais da comunicação, entretanto ela só se concretizou praticamente um mês depois dos acontecimentos, tempo suficiente para a CNBB inteirar-se sobre os fatos, porém tardio para o jornalismo e para os próprios religiosos, que a essa altura já tinham sido torturados.

Com relação ao bispo dom Casaldáliga e ao padre Zufferey, quase todo o agendamento da igreja se deu por meio de entrevistas, embora também não seja possível distinguir nas notícias quando se trata de entrevista coletiva ou de declaração individual ao jornal. Quase não há presença de notas. Esses dois casos ocorreram em 1977, quando já se falava em abertura política. Isto talvez tenha sido determinante para a atuação mais livre da CNBB e da imprensa.

Ao final dos anos 1970, com o declínio da ditadura, a igreja não tinha mais a mesma preocupação que outrora tivera em cuidar das palavras que se tornariam públicas, pois conforme elas fossem interpretadas e apresentadas pela imprensa poderiam agravar ainda mais as relações entre a instituição religiosa e o Estado. A imprensa também vivia um período de mais liberdade, embora ainda houvesse controle. Por isso os pronunciamentos da CNBB deixaram de ser escritos e passaram a ser verbais, de modo diferente do que ocorrera no período mais rígido do regime, durante o qual a CNBB atuou mais por meio de divulgação de notas, cuja maioria foi publicada na íntegra pelos jornais, como um ritual estratégico (LACERDA, 2007).

Além das entrevistas, nas quais a fonte concede informações a um repórter que vá buscá-la no processo de apuração do fato jornalístico, havia também a atuação da CNBB por meio de notas: informação credível e oficial emitida pelas organizações com a finalidade de ajudar no processo de apuração jornalístico. Nesta lógica: a fonte procura o repórter e/ou seus públicos.

\section{As notas: um ritual estratégico}

De acordo com Tuchman (1999, p. 74), “o uso de certos procedimentos perceptíveis ao consumidor de notícia protege o jornalista dos riscos da sua atividade, incluindo os críticos". Os riscos aos quais a autora se refere são aqueles que podem prejudicar tanto o próprio profissional como a organização para a qual trabalha. Para Tuchman (1999, p. 78), "cada notícia afeta poten- 
cialmente a capacidade dos jornalistas no cumprimento de suas tarefas diárias, afeta a sua reputação perante os seus superiores, e tem influência nos lucros da organização". Tuchman faz essa reflexão a partir da percepção do leitor. Por meio de rituais estratégicos, por exemplo, o uso das aspas nas declarações das fontes, o jornalista defende a si mesmo e ao próprio jornal das eventuais críticas que o leitor da notícia possa fazer, inclusive de processos de difamação.

Os rituais estratégicos adotados pela imprensa durante o regime militar no Brasil adquiriram, entretanto, outra dimensão. Os riscos a que Tuchman (1999) se refere eram grandes e poderiam ter consequências muito graves. Estavam em perigo não somente a reputação do profissional e os lucros da empresa, mas a própria vida. Por isso, os rituais estratégicos foram significativos no processo de construção da notícia durante um período de censura e de violação aos direitos humanos.

Dos rituais observados, o mais frequente nas matérias analisadas foi a publicação de notas divulgadas pela CNBB. Foram publicadas, ao todo, 13 notas sobre os cinco casos de religiosos acusados de subversão (Tabela 1).

\section{Caso}

Padres Michel Le-Ven, Xavier Berthon,

Hervé Crouguennac.

Padres dominicanos

Padre Jacques Jentel

Padre Romain Zufferrey

Dom Pedro Casaldáliga

Total
$\mathrm{N}^{\circ}$. de Notas por Caso

3

5

2

2

1

13

Tabela 1: $\mathrm{N}^{\circ}$. de Notas Divulgadas pela CNBB por Caso Analisado Fonte: Arquivo jornalístico da CNBB

A maioria das notas se refere aos três primeiros acontecimentos, ou seja, aos religiosos franceses, dominicanos e ao padre Jentel. Acerca dos dois últimos, a CNBB também divulgou notas, mas elas não tiveram a mesma importância que as anteriores. Nos casos de dom Casaldáliga, e do padre Zufferrey, o pronunciamento verbal já se tornara mais interessante do que a divulgação de notas, tanto para a CNBB como para a imprensa, visto que, por meio da fala, há mais liberdade de expressão, embora, durante os períodos mais rigorosos da ditadura, as notas tivessem sido importantes para as 
duas instituições. Para a CNBB, as notas asseguravam a integridade do que fora dito à imprensa a respeito dos fatos. Representavam a segurança de que o pronunciamento não seria distorcido, o que poderia colocar em risco suas relações com o Estado. Para a imprensa, a publicação das notas era uma forma de dizer: "esta afirmação pertence a qualquer pessoa, menos ao repórter" (TUCHMAN, 1999, p. 82), evento já considerado pela autora, no arcabouço da Teoria da Notícia.

O uso das notas assemelha-se ao das citações e ao uso das aspas, que Tuchman (1999, p. 81) conceitua como sendo rituais estratégicos: "ao inserir a opinião de alguém, eles (os jornalistas) acham que deixam de participar na notícia e deixam os 'fatos' falar". Essa estratégia foi importante para os jornalistas brasileiros durante a ditadura, pois lhes garantiu segurança perante as possíveis ações repressivas do regime. As notas serviram para distinguir bem a quem pertencia a fala, ou seja, que ela era da CNBB e não do jornalista que noticiava os fatos. Os jornais, por isso, chegaram a publicar mais de uma nota em uma única edição.

As 13 notas da CNBB foram publicadas em 23 jornais (Tabela 2), a maioria na íntegra. Deve-se levar em consideração também que essas notas foram divulgadas em pequeno intervalo de tempo, em média um mês para cada caso. As notas registradas dizem respeito somente ao posicionamento da $\mathrm{CNBB}$, de seus bispos ou de instituições estritamente ligadas a ela como a Comissão Brasileira Justiça e Paz e as arquidioceses nas quais ocorreram os fatos. Não fazem parte desta análise as notas divulgadas por outras instituições religiosas, por exemplo, as das congregações às quais pertenciam os religiosos, por serem organismos independentes da Conferência.

\begin{tabular}{lcc}
\multicolumn{1}{c}{ Caso } & $\mathrm{N}^{\mathrm{o}}$. de Matérias & $\mathrm{N}^{\mathrm{o}}$. de Matérias com \\
Notas & & \\
Padres Michel Le-Ven, Xavier Berthon, Hervé & 10 & 7 \\
Crouguennac & 15 & 8 \\
Padres dominicanos & 5 & 4 \\
Padre Jacques Jentel & 15 & 3 \\
Padre Romain Zufferrey & 8 & 1 \\
Dom Pedro Casaldáliga & 53 & 23 \\
Total & & \\
\hline
\end{tabular}

Tabela 2: Número de Matérias com Notas

Fonte: Arquivo jornalístico da $\mathrm{CNBB}$ 
Ao observar os dados das Tabelas 1 e 2, percebe-se que as notas foram mais difundidas nos casos dos religiosos franceses e dominicanos. Isso pode ter acontecido pelos motivos a seguir detalhados.

1) Percebe-se, pela leitura das matérias, certa resistência da CNBB em se pronunciar sobre os dois casos, pois eles estavam entre os primeiros conflitos que deixaram a igreja "na berlinda". Eles ocorreram no final dos anos 1960, logo após a decretação do AI-5 e envolveram mais de um religioso. As acusações aos religiosos franceses provinham de sua relação com a Pastoral Operária e as dos dominicanos, de sua participação tanto na Aliança Libertadora Nacional (ALN) como no movimento estudantil. A CNBB não tinha, até então, lidado com problemas dessa proporção, envolvendo inclusive religiosos estrangeiros, além de encontrar-se em posição neutra com relação ao regime. Para evitar agravamento em sua relação com o Estado, ela procurou primeiro apurar os fatos, para depois manifestar-se.

2) Outro aspecto relevante foi a preocupação da igreja com a distorção das informações. Dom Luciano Mendes de Almeida ${ }^{4}$ afirmou que a imprensa distorcia muito os pronunciamentos da igreja, o que poderia prejudicar suas relações com o Estado. Por meio de notas, não haveria, portanto, como a imprensa manipular essas declarações.

3) Visto que a censura ainda não era total, como ocorreu no início da década de 1970, mas que já existiam as repressões, talvez fosse mais conveniente para a imprensa publicar uma nota na íntegra, pois, dessa forma, ela se tornaria isenta de qualquer acusação, podendo afirmar: "foi a CNBB quem disse".

Em contraposição ao número de notas publicadas sobre os casos dos religiosos dominicanos e franceses, o ano de 1977 apresenta pouquíssimas notas, tanto a respeito do caso do padre Zufferrey como o do bispo dom Casaldáliga. Como as forças do regime militar não eram mais as mesmas, nem acerca da imprensa nem sobre as instituições, as notas foram substituídas por declarações verbais. Em ambos os casos, a CNBB, na defesa desses dois religiosos, atuou mais como promotora de notícia do que como fonte de informação.

As 13 notas divulgadas pela imprensa foram classificadas no presente estudo como: de esclarecimento, de crítica e de denúncia. Algumas se inserem em mais de uma categoria. Podem ser, por exemplo, de esclarecimento e de crítica ou de denúncia e de crítica.

4 Dom Luciano foi presidente da CNBB no final da década de 1970. A entrevista foi realizada durante a $44^{\mathrm{a}}$. Assembleia Geral da CNBB, em maio de 2006, como parte integrante do processo de apuração de Lacerda (2007). 
As notas de esclarecimento limitavam-se a descrever o que estava ocorrendo no momento. Por exemplo, no caso dos religiosos franceses, em 1968, o Secretariado de Opinião Pública da CNBB lançou um comunicado apenas para afirmar que a situação dos padres se encaminhava para "o indispensável esclarecimento". Diz a nota:

O Secretariado Nacional de Opinião Pública da Conferência Nacional dos Bispos do Brasil está autorizado a informar que Dom Aloísio Lorscheider, Secretário-Geral da CNBB, com o objetivo de acompanhar junto à própria fonte o desenrolar dos acontecimentos relativos à prisão dos padres e do diácono assuncionista, esteve em Belo Horizonte, em contato prolongado com D. João Rezende, D. Serafim, o Conselho Presbiteral e o Provincial dos Padres Assuncionistas. Nesta ocasião, D. Aloísio teve a oportunidade de verificar, pessoalmente, que a situação caminha para o indispensável esclarecimento. Em seguida foi ele até São Paulo, a fim de manter o Cardeal Rossi, presidente da $\mathrm{CNBB}$, inteirado do que realmente ocorre na capital mineira, e tratar, ao mesmo tempo, de assuntos de rotina da própria CNBB (O GLOBO, 11/12/68).

A nota sobre a expulsão do padre Jentel é outro exemplo de pronunciamento que se limitou a descrever os fatos. Apesar de fazer referência à brutalidade que o padre foi imobilizado, a CNBB não critica a decisão do governo de expulsar o sacerdote do país.

Padre Francisco Jentel retornou ao País, via Estados Unidos, desembarcando normalmente no aeroporto de Brasília, no dia 1 do corrente mês. Vinha da França, onde estivera em visita aos seus familiares e fora fazer cursos de atualização. Recorde-se que em maio de 1973 o mesmo fora condenado pela Justiça Militar de Campo Grande, MT, após conhecidíssimo processo, onde fora voto vencido o juiz auditor (cf. 'Notícias' CNBB, n. 22, 1/6/1975). Recorrida a sentença junto ao Superior Tribunal Militar, por unanimidade de votos, deu provimento à apelação interposta em favor do padre Francisco Jentel para anular a sentença condenatória, determinando fosse ele posto imediatamente em liberdade. Entendeu o Tribunal que os fatos a que se referia o processo (conflito entre os posseiros e os agentes da Companhia de Colonização Codeara) constituíram fatos que devem ser apreciados pela Justiça comum, sendo incompetente a Justiça Militar, já que existia qualquer conteúdo subversivo nas ações praticadas, seja pelos agentes da empresa (igualmente processados), seja pelo padre Francisco Jentel' (cf. Notícias CNBB, n. 21, 24/5/1975). Logo em seguida viajou à França, conforme seu desejo pessoal, de onde retornou a 1 de dezembro. Regressando ao Brasil e nada constando oficialmente em seu passaporte que o impedisse de fazê-lo, dirigiu-se a Fortaleza, em visita 
a dom Aloísio Lorscheider, presidente da CNBB e arcebispo local. Hóspede do mesmo, na manhã do dia 12, por volta das 7 horas, quando se dirigia, a pé, ao centro da cidade, juntamente com outro sacerdote, foi o padre Jentel violentamente imobilizado e seqüestrado por quatro desconhecidos, colocado num automóvel e levado a lugar ignorado. Posteriormente, ainda no correr da manhã do mesmo dia, foi localizado no Departamento da Polícia Federal de Fortaleza. Conduzido ao Rio de Janeiro na noite do mesmo dia, está preso em dependências da Marinha. Através de comunicação telefônica do senhor ministro da Justiça, ao senhor cardeal do Rio de Janeiro, foi a CNBB informada de que o senhor presidente da República assinou decreto, no dia de hoje, determinando fosse o padre Francisco Jentel expulso do País (FOLHA DE S. PAULO, 16/12/1975).

A respeito do caso dos dominicanos, a instituição, embora não tenha se limitado a descrever o ocorrido, não toma qualquer atitude em defesa dos religiosos que estavam sendo torturados pelo regime. Ao contrário, admite a possibilidade da culpa e, ao mesmo tempo, pede para que ela não seja generalizada a toda a congregação ou mesmo a toda a igreja. Apesar disso, a nota escrita pelo presidente da CNBB, dom Rossi, faz apelo à observância dos direitos humanos, tanto na defesa dos frades como no tratamento que eles estavam recebendo. Esta nota pode, por isso, ser classificada como de esclarecimento e também de crítica.

Regressando dos trabalhos do Sínodo, defronto-me com os dolorosos acontecimentos dos últimos dias, nos quais estão envolvidos inclusive alguns sacerdotes e seminaristas da Ordem Dominicana. Como presidente da Comissão Central da Conferência Nacional dos Bispos do Brasil e como Arcebispo Metropolitano, tenho o máximo empenho em conhecer, para além do noticiário da imprensa, a exatidão dos fatos. Enquanto não me é possível formular e emitir um juízo exato sobre os episódios, desejo ao menos dirigir uma palavra aos católicos de São Paulo e aos homens do meu país: 1. Não tememos enfrentar os fatos desde que eles sejam averiguados, acima das paixões, na verdade e na justiça. 2. Como em outros episódios, não reivindicamos para sacerdotes e religiosos, só porque o são, regalias e privilégios. Mas creio dever reclamar para eles, como para quaisquer cidadãos, a observância dos direitos humanos quer na sua defesa quer no tratamento que recebem. 3. Declaro que não podemos aceitar, por serem semi-evangélicos e até contrários ao bem-estar de nosso país, métodos de violência e de terrorismo. Menos ainda podemos concordar com a participação, na prática destes métodos, de sacerdotes, religiosos e de seminaristas ou candidatos à vida religiosa. 4. Devo repelir porém, com igual energia, que, com qualquer intuito, a culpa pessoal de alguns, mesmo comprovada, seja generalizada 
para toda uma família religiosa, todo o clero - e até toda a Igreja. Igualmente rejeito, como presidente da Comissão Central da $\mathrm{CNBB}$, que se confunda malevolamente na mesma condenação a ação mal orientada de alguns com os propósitos e atividades de inúmeros bispos, sacerdotes ou leigos que, na mais profunda fidelidade ao espírito da Igreja, de acordo com as normas do Vaticano II e da Conferência de Medellín, se consagram a um trabalho de evangelização que os aproxima dos pobres e os empenha numa tarefa de autêntica promoção humana. 5. Alimento o desejo e a esperança de que destes acontecimentos traumatizantes possa ainda surgir um clima de entendimento e união em nosso país e o povo possa guardar sua confiança na retidão de intenções humanas e de ação da Igreja no Brasil, que quer manter-se fiel a Cristo e à orientação do Papa Paulo VI (JORNAL DO BRASIL, 11/11/1969).

Os casos do padre Jentel e dos dominicanos tiveram consequências mais graves, se comparados aos demais analisados. A CNBB não atuou com a mesma força como nos casos dos franceses, do sacerdote suíço Zufferrey e de dom Pedro Casaldáliga. Em relação aos religiosos franceses, a CNBB posicionou-se de forma mais crítica e defensiva.

As acusações que, dia a dia, mais se avolumam contra a Igreja em nosso país pedem um esclarecimento autorizado por parte da Conferência Nacional dos Bispos do Brasil. A Igreja, em seus membros, é tachada de subversiva. Se a Igreja, nos dias atuais, reivindica uma participação ativa na procura do desenvolvimento integral do homem e de todos os homens, ela não está exorbitando de seu campo específico que é o religioso: esta procura é parte intrínseca de sua missão de serviço à humanidade. Mas ela está ao mesmo tempo consciente que a sua única motivação nasce da palavra de Cristo, do Evangelho, que deverá encarnar-se sempre mais em todos os campos da atividade humana, seja o político como o econômico, o social e o cultural. Ao repudiar todo e qualquer sistema econômico, político, social e cultural de inspiração ateia e materialista, ela proclama sua visão integral do homem liberto de qualquer servidão, e ao propugnar a busca cristã da Justiça ela visa aquela emancipação total que permita ao homem usufruir da liberdade dos filhos de Deus. Isto exige em nossos dias transformações profundas em nós mesmos e na sociedade. Portanto, esta exigência de transformações que propugna pela mudança de uma ordem econômica, política, social e cultural manifestadamente injusta não deve ser confundida com subversão de autênticos valores humanos e cristãos que todos nós queremos. (...). No que diz respeito à prisão de padres e um diácono em Belo Horizonte, esclarecemos que não entramos no mérito da legitimidade ou não desta prisão. Esperamos que a justiça de nossas autoridades corresponda à imagem de honradez e hombridade que todos dela queremos ter. Devemos registrar, no entanto, que 
estranhamos que não se tenham dado às respectivas autoridades eclesiásticas as devidas informações requeridas pelo caso para um possível esclarecimento e defesa das pessoas indiciadas. Queremos que as justas reivindicações do povo, feitas à sombra de nossa bandeira, não se façam jamais de um modo violento, pois a violência, afirma mais que uma vez Paulo VI, não é evangélica nem cristã. Infelizmente, nesta quadra delicada para o nosso país, estão surgindo com certa freqüência tensões e conflitos, perfeitamente evitáveis se houvesse maior prudência, objetividade e respeito pelos valores básicos da sociedade: verdade, justiça, liberdade e amor. Somente nesta linha logramos a verdadeira paz e compreensão e se evitarão os choques entre as pessoas que realmente amam o Brasil e o seu povo (JORNAL DO BRASIL, 5/11/1969).

Nessa nota sobre os padres franceses, a CNBB defendeu a Igreja como um todo das acusações de subversão. Publicada na íntegra por alguns jornais, ela é uma nota bem mais reflexiva do que as já observadas. É também mais audaciosa, à medida que questiona tanto a ordem política que levou os religiosos à prisão como a falta de provas. Algo similar ocorreu em casos posteriores. Nos casos do padre Zufferrey e de dom Pedro Casaldáliga, a CNBB teve atuação mais ativa do que na dos religiosos franceses. Suas declarações eram verbais e não mais por meio de notas. Nesse período, o governo passava por uma crise decisiva para a queda da ditadura, a imprensa e a igreja já encontravam liberdade para atuar, ou seja, a censura, embora ainda existisse, não era mais tão rigorosa como nos anos anteriores. As instituições passaram a agir com maior liberdade. As notas foram, pois, deixadas de lado, tanto pela CNBB como pela imprensa. Os bispos passaram da atitude de autodefesa para a de denúncia, como mostram os seguintes textos jornalísticos:

O secretário da Conferência Nacional dos Bispos do Brasil, dom Ivo Lorscheiter, informou ontem no Rio que 'recebeu de fontes fidedignas de Brasília e Goiás um alerta no sentido de que seria iminente a expulsão de dom Pedro Casaldáliga do Brasil. (...) Diante da ameaça iminente da expulsão de dom Pedro, afirmou dom Ivo Lorscheiter, "o secretário geral da CNBB apela intensamente aos órgãos responsáveis do governo para que um ato de injustiça e hostilidade à Igreja não se consuma" (FOLHA DE S. PAULO, 30/07/77).

Ainda se considera:

D. Aloísio disse que o caso do Padre Romain será examinado pela Comissão Justiça e Paz, que orientará a ação da CNBB. Acrescentou que tudo será feito para apoiar o sacerdote suíço e que espera que a Justiça funcione. "Normal- 
mente, nesses casos, não aceitamos acordos diplomáticos. O Ministro da Justiça sabe disso. Não seria digno à condição de sacerdotes. Nós estamos sempre do lado da verdade”, concluiu (JORNAL DO BRASIL, 22/07/1977).

Nas poucas notas divulgadas pela igreja, em 1977, observa-se que seu teor é diferente daquelas divulgadas no final dos anos 1960. Os bispos não tinham mais medo de se expressarem; eram firmes em seus posicionamentos a favor dos direitos humanos e da justiça social.

Notas, entrevistas e declarações verbais não foram as únicas estratégias usadas pela igreja para pautar a imprensa, há outras bastante interessantes por fugirem à rotina do agendamento feito pela $\mathrm{CNBB}$.

\section{Meios alternativos de agendamento da imprensa}

Também constaram nos jornais outras formas alternativas de agendamento da imprensa feitas pela CNBB ou por instituições ou pessoas ligadas a ela. Das 53 notícias analisadas no estudo, oito apresentam, geralmente na íntegra, telegramas e mensagens de solidariedade à instituição e aos religiosos acusados de praticar atividades subversivas. A maioria das mensagens refere-se aos casos de dom Casaldáliga e dos três religiosos franceses. Exemplificam-se, a seguir, algumas dessas manifestações divulgadas pela igreja e publicadas pelos jornais:

FORTALEZA (O GLOBO) - O Departamento Arquidiocesano desta capital, cumprindo instruções do Arcebispo Dom José Medeiros Delgado, fez divulgar uma nota de solidariedade aos padres presos em Minas, lida em todas as igrejas da capital e do interior durante as missas.

Os padres presos em Minas Gerais - diz a nota - desmentiram qualquer participação em atividades de guerrilhas. Eles, como outros, sofrem perseguição e calúnia por amor da Justiça como sofreram os mártires da Igreja primitiva. Trabalham pela promoção da classe operária, mas sem violência (O GLOBO, $11 / 12 / 68)$.

Ontem, a CNBB recebeu da Conferência Episcopal Francesa telegrama de apoio e solidariedade nos seguintes termos: "Em nome da Conferência Episcopal Francesa vos asseguro apoio fraternal na defesa dos Direitos do Homem e preocupação comum à prática do Evangelho”. Paul Huet Pleuroux. A CNBB recebeu ainda outras manifestações de apoio. 'O Movimento Cursilhos de Cristandade do Brasil renova total solidariedade à $\mathrm{CNBB}$, visto referida medida atingir frontalmente a presença e a unidade da Igreja na realidade brasileira'. Também o arcebispo de Belo Horizonte, Dom João Rezende Costa, em nome dos bispos de Minas Gerais e Espírito Santo, enviou mensagem de 
solidariedade à posição da CNBB em defesa de Dom Pedro.

Dom Alberto Ramos, Arcebispo de Belém, em nome dos bispos do Pará, Maranhão, Piauí e Ceará, também manifestou apoio e solidariedade à posição da CNBB pela permanência, no Brasil, do bispo Dom Pedro Casaldáliga. Antes, a CNBB já havia recebido apoio dos bispos de Pernambuco, Alagoas, Rio Grande do Norte, São Paulo, Paraná, Santa Catarina, Goiás e Mato Grosso (O GLOBO, 2/08/77).

Constam também, como estratégias de agendamento, uma vigília realizada pela arquidiocese de Olinda e Recife, organizada pelo arcebispo dom Helder Câmara, com o objetivo de dar apoio espiritual ao padre Zufferey, em 1977, e encontros do presidente da CNBB, dom Rossi com o presidente da República, Garrastazu Médici e com outras autoridades (Figuras 1 e 2).

\section{Encontro de d. Agnelo Rossi com autoridade}

Serviço Local e das zurscis do Rio e de Belo Horizonte

curdeal-arcebispo 5o Paulo, d. Agnelo 1, un representante Exiercito e um ofi- clal dos altos escalóes de Minas Gerais mantiveram, no fim da semana, uma reunlâo que teve como tema principal o eplsodio das prisobes dos padres, em Minas, acusados pelas autoridades militares de esta- rem envolvidos em atividades subversivas.

Toda a documentacâo apreendida em poder daqueles sacerdotes fol apresentada ao cardealarcebispo de Såo Paulo. para que este, pela sua alta posiçăo (ê o prestdente da Conferencla Nacional dos Bispos do ridades milit Brasil), ajude na pro- năo dessem cura de uma soluçáo sa- aos documento tisfatoria para o caso.

Segundo certas versōes, ao rinal do enconbem que os da reuniáo pe sem em compl

Figura 1: Notícia aborda encontro de dom Rossi com autoridades, sobre religiosos franceses

Fonte: Folha de S. Paulo, 8/12/68

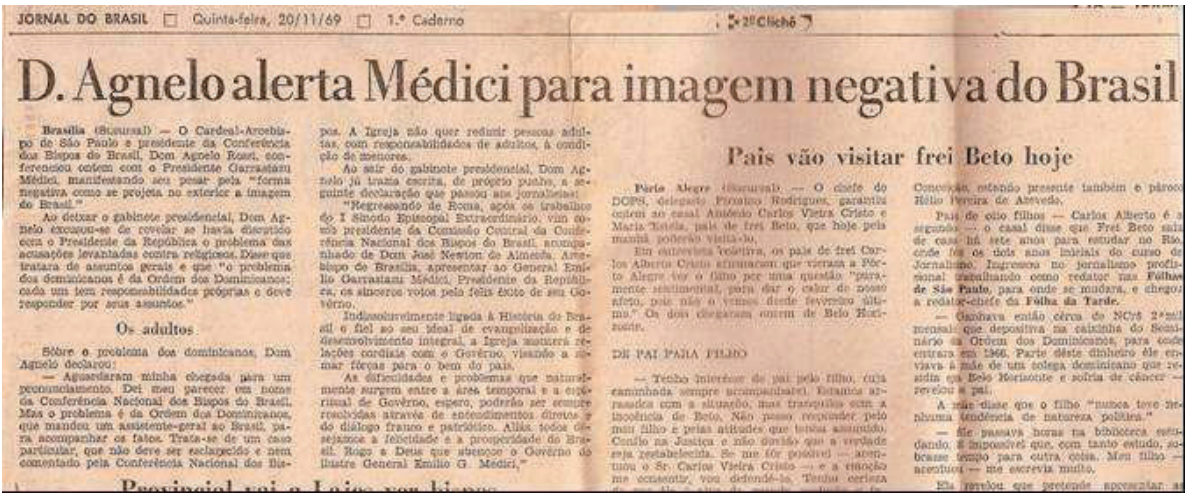

Figura 2: Notícia sobre encontro de dom Rossi e presidente Médici, na ocasião da prisão de religiosos dominicanos

Fonte: Jornal do Brasil, 20/11/69 
Além das mensagens de solidariedade, da vigília e de encontros com autoridades, consta, nas matérias analisadas, a publicação, na íntegra, da homilia feita, em 1968, pelo arcebispo de Belo Horizonte, dom João Rezende Costa, sobre a prisão dos religiosos franceses, a qual foi lida em todas as paróquias da arquidiocese (Figura 3).

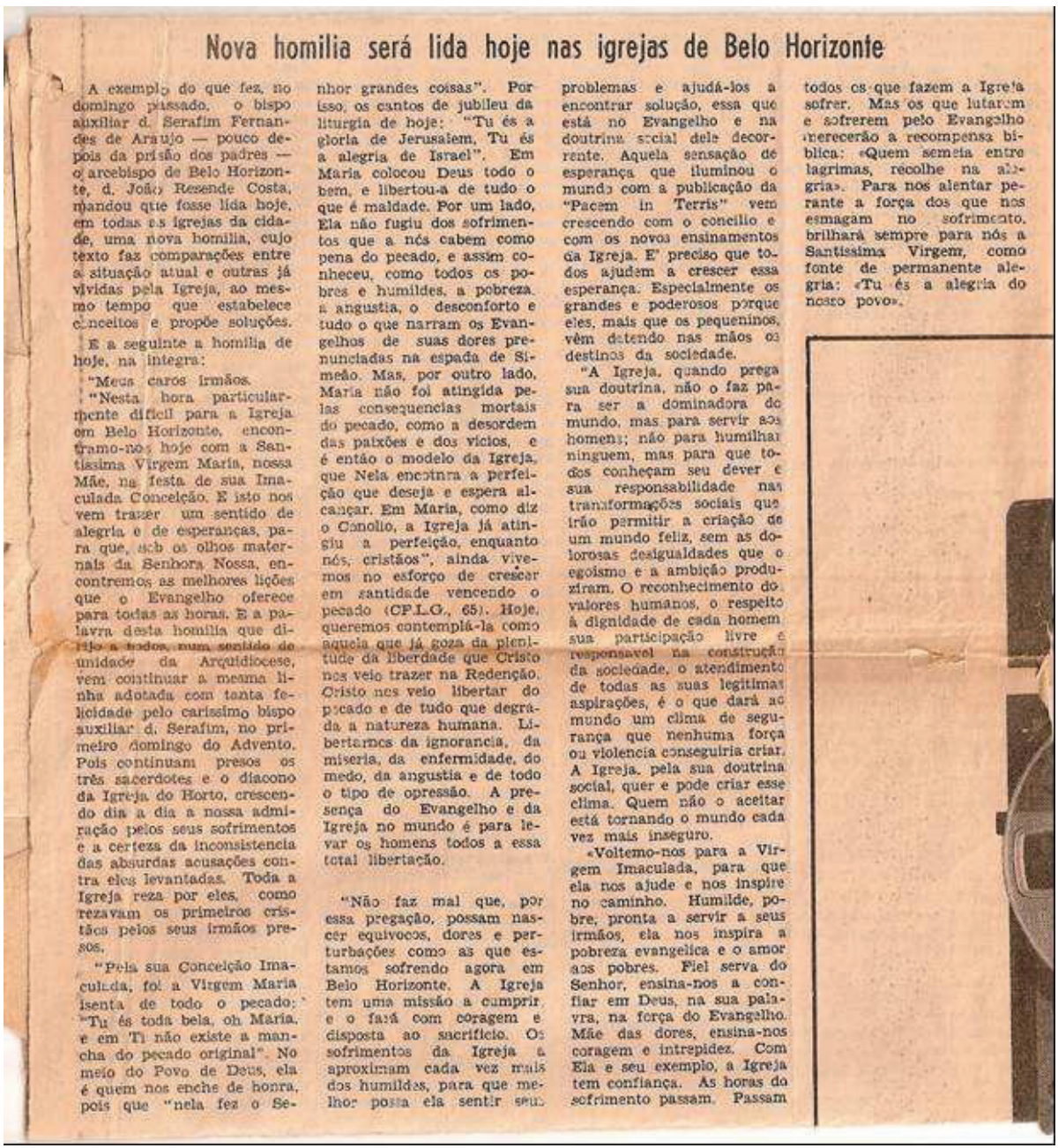

Figura 3: Homilia do arcebispo de Belo Horizonte, dom Rezende, publicada na íntegra pelo jornal

Fonte: Folha de S. Paulo, 8/12/68 
Todas essas estratégias de agendamento revelam a atuação da CNBB, de bispos e de instituições ligadas a ela como promotoras de notícia. Sua presença nos meios de comunicação impressos não significa, porém, que a forma como os jornais noticiaram os acontecimentos estava de acordo com as expectativas do agendamento. Nem sempre houve a correlação entre o agendado pela instituição religiosa e o modo que o jornal enquadrou a notícia. Diversos fatores provocaram esse desencontro entre igreja e imprensa, como se evidencia na análise da cobertura da imprensa a respeito dos cinco casos de religiosos acusados de praticar atividades subversivas.

\section{Considerações finais}

O processo de produção da notícia (MOLOTCH e LESTER, 1999) leva em conta o encontro entre promotores de notícias e jornalistas. Entretanto, à época da ditadura militar no Brasil, o cerceamento à opinião e as dificuldades relativas à liberdade de expressão e liberdade de imprensa, do período, exigiram dos atores sociais certa cautela para alcançar o espaço público, espaço midiático e a opinião pública. Nesse sentido, a hipótese do agendamento é utilizada para dar sentido aos significados extraídos da análise de conteúdo, a partir de jornais e publicações veiculadas durante o regime militar. Há a limitação metodológica da própria Agenda Setting, no que concerne à sua discussão epistemológica na Comunicação: ser uma hipótese ou uma teoria. No entanto, para além da epistemologia, ela é bem operacional ao permitir o enquadramento e o fluxo noticioso de agendas, ou seja, de pautas que podem ser (ou não) de diversos ramos da sociedade. Nesse sentido, a partir de uma abordagem inédita, este artigo buscou compreender como a CNBB atuou para pautar a mídia, ou seja: ser promotora da notícia.

O Agendamento trabalha com o conteúdo circulante no Jornalismo, a agenda pública, além de acontecimentos da vida privada. Também estão em pauta agendas de políticas públicas e governamentais, além de fatos e eventos que configurem aparelho do Estado. O artigo alcança o objetivo de resgatar como os news promoters (assessores, organizações, no caso, a CNBB) se relacionam com os news assemblers (repórteres, editores e redatores) negociando sentidos a serem ofertados no noticiário para os news consumers: não somente o público leitor, mas, também, os cidadãos no processo social de construção de acontecimentos (MOLOTCH; LESTER, 1999, p. 42). Ainda mais durante o regime militar, quando essa negociação de sentido era cerceada e as relações eram bem tensas. Nesse quesito, mais 
que notícia, a CNBB foi catalisadora do discurso e do meio religioso organizado (catolicismo), no Brasil, em prol da luta pelos direitos humanos. As notas como ritual estratégico e meios alternativos de agendamento da Conferência e de bispos e instituições ligadas a ela, além de práticas históricas utilizadas para superar as restrições do regime autoritário, configuram práticas noticiosas: legítima intersecção entre religião e sociedade, para muito além dos templos, ritos.

\section{Referências}

FOLHA DE S. PAULO. Governo expulsa do País o pe. Jentel. 16/12/1975.

FOLHA DE S. PAULO. Lorscheider denuncia. 30/07/77.

HACKETT, Robert. Declínio de um paradigma? A parcialidade e a objetividade nos media noticiosos. In: TRAQUINA, Nelson (org.). Jornalismo: questões, teorias e estórias'. Lisboa: Vega, 1999.

HALL, Stuart et al. A produção social das notícias: O mugging nos media. In: TRAQUINA, Nelson. Jornalismo: questões, teorias e 'estórias', 2. ed. p. 224-248. Lisboa: Vega, 1999.

JORNAL DO BRASIL. Comissão da CNBB examina trabalho de padre suíço e deverá dar-lhe endosso. 22/07/1977.

JORNAL DO BRASIL. D. Agnelo só quer Direitos Humanos. 11/11/1969.

JORNAL DO BRASIL. Secretário da CNBB diz que o caso dos padres caminha para o esclarecimento. 11/12/68.

JORNAL DO BRASIL. Sem Título. 5/11/1969.

LACERDA, Eliane Muniz. O jornalismo nos limites da liberdade: um estudo da cobertura da imprensa sobre os casos dos religiosos acusados de praticar atividades subversivas durante o regime militar, 2007, 137s. Dissertação (Mestrado em Comunicação) - Universidade de Brasília, Brasília, 2007.

LORSCHEDER, Dom Aloísio. Entrevista realizada em outubro de 2006.

MARCONI, Paolo. A censura política na imprensa brasileira. São Paulo: Global, 1980.

MCCOMBS, Mawell E.; SHAW, Donald L. A evolução da pesquisa sobre o agendamento: vinte e cinco anos no Mercado das idéias. In: TRAQUINA, Nelson. O Poder do Jornalismo: Análise e Textos da Teoria do Agendamento, p. 125-134. Coimbra: Minerva, 2000.

MENDES, Dom Luciano. Entrevista realizada em maio de 2006.

MOLOTCH, Harvey e LESTER Marilyn. As notícias como procedimento intencional: acerca do uso estratégico dos acontecimentos de rotina, acidentes e escândalos. In: TRAQUINA, Nelson (org.). Jornalismo: Questões, teorias, estórias. Lisboa (Portugal): Vega, 1999.

MOTTA, Luiz Gonzaga. Pesquisa em jornalismo no Brasil: o confronto entre os paradigmas midiacêntrico e sociocêntrico. Comunicação apresentada no Congresso da IAMCR. Porto Alegre, 2004. 
O ESTADO DE S. PAULO. Igreja aguarda prova de culpa. 6/12/69.

O ESTADO DE S. PAULO. Paris intercede pelos sacerdotes. 7/11/68. O GLOBO. D. Agnelo apoia arcebispo. 11/12/68.

O GLOBO. Camargo nega expulsão de Casaldáliga. 30/07/77.

O GLOBO. Ministério nega estudo para expulsão de bispo. 2/08/77.

SERBIN, Kenneth P. Diálogos na Sombra: Bispos e militares, tortura e justiça social na ditadura. Traduzido por: Carlos Eduardo Lins da Silva. São Paulo: Companhia das Letras, 2001.

SOARES, Ismar de Oliveira. Do Santo Ofício à Libertação: o discurso e a prática do Vaticano e da Igreja Católica no Brasil sobre a comunicação social. São Paulo: Paulinas, 1988. TUCHMAN, Gaye. La producción de la noticia. Barcelona: GG, 1983.

. Contando "estórias". In: TRAQUINA, Nelson. Jornalismo: questões, teorias e 'estórias’, 2. ed. Lisboa: Vega, 1999.

UCHOA, Pe. Vigílio. Entrevista realizada em novembro de 2005.

Submetido em: 15-8-2016

Aceito em: 13-2-2018 